\title{
Sasang Constitution as a Risk Factor for Diabetes Mellitus: A Cross-Sectional Study
}

\section{Tae-Gyu Lee, Byunghee Koh and Sookyung Lee}

Department of Sasang Constitutional Medicine, College of Oriental Medicine, Kyung Hee University, South Korea

\begin{abstract}
Sasang Constitutional Medicine, which is a branch of traditional Korean medicine, states that medications for diabetes should be individualized according to the patient's individual constitution. However, the effect of constitution on diabetes has not been evaluated to date. Therefore, this study was conducted to determine if constitution is an independent risk factor for diabetes by comparing the prevalence and odds ratios (ORs) of the disease according to constitution. The medical records of 1443 adults who had been examined and classified based on their constitution at Kyung Hee University Hospital in Seoul, Korea were reviewed. A chisquared test and Fisher's exact test were used to compare the prevalence of diabetes according to constitution, and multiple logistic regression was used to calculate the ORs for diabetes. The prevalence of diabetes differed significantly according to constitution $\left(\chi^{2}=36.20, \mathrm{df}=2\right.$, $P<0.001)$. Specifically, the prevalence of the disease was higher in Tae-eumin $(11.4 \%)$ individuals than in Soyangin $(5.0 \%)$ or Soeumin $(1.7 \%)$ individuals. In addition, multiple logistic regression revealed that Tae-eumin individuals had a greater risk for diabetes than Soeumin individuals. When compared to Soeumin individuals, the adjusted ORs were 2.01 (95\% CI 0.77-5.26) for Soyangin individuals and 3.96 (95\% CI 1.48-10.60) for Tae-eumin individuals. These results show that constitution has a significant and independent association with diabetes, which suggests that constitution is an independent risk factor for diabetes that should be considered when attempting to detect and prevent the disease.
\end{abstract}

Keywords: Sasang Constitutional Medicine - constitution - diabetes - prevalence - risk factor

\section{Introduction}

The number of diabetes patients is rapidly increasing worldwide. Indeed, there were 171 million diabetes patients in 2000, and that number is expected to increase to 366 million by 2030 (1). Diabetes gives rise to microvascular and macrovascular complications and results in a socioeconomic burden (2-4). For example, the American Diabetes Association (ADA) estimated that the national costs associated with diabetes in the United States for 2007 were $\$ 174$ billion (5). To reduce

For reprints and all correspondence: Sookyung Lee, M. $\mu$ Integrative Cancer Center, East-West Neo Medical Center, Kyung Hee University, 149 Sangil-dong, Gangdong-gu, Seoul 134-727, South Korea. Tel: + 822-440-6229; Fax: +82-2-440-7287; E-mail: sookyung@khu.ac.kr such losses, it is necessary to prevent diabetes by managing risk factors. It is well known that type 2 diabetes occurs more frequently in older individuals and among certain ethnicities, as well as individuals that are obese, do not exercise, have a family history of the disease, or have previously been diagnosed with gestational diabetes mellitus, polycystic ovary syndrome, hypertension, dyslipidemia, impaired glucose tolerance or impaired fasting glucose (6-11).

Sasang Constitutional Medicine (SCM) is a branch of traditional Korean medicine that classifies human beings into four constitutions (Soeumin, Soyangin, Tae-eumin and Taeyangin). SCM states that a patient's susceptibility to pathology or drug response differs by constitution. This theory also applies to diabetes, which is classified into 'Sik-so' for Soeumin individuals, 'So-gal' for 
Soyangin individuals and ' $J o-y u l$ ' for Tae-eumin individuals. Accordingly, medications administered for the treatment of diabetes are specific for individuals of various constitutions (12-14). As a result, traditional Korean medical doctors treat and manage clinical cases of diabetes and its complications according to the constitution of the afflicted patients (15-21).

However, despite such practical applications, there have been no studies conducted to evaluate the effects of constitution on diabetes. Therefore, this study was conducted to determine if constitution can be used as an independent risk factor for diabetes by comparing the prevalence and odds ratios (ORs) of the disease according to constitution.

\section{Methods}

\section{Subjects}

This study was conducted by retrospective chart review upon a total of 2172 individuals who took health examinations from January 2003 to June 2003 at Kyung Hee University Hospital in Seoul, Korea and were initially classified by constitution using the revised questionnaire for the Sasang Constitution Classification II (QSCC II ${ }^{+}$) (22-24). In this study, all outpatients visiting hospital during the defined duration were included into subjects without practicing a specific sampling method to determine the sample size before reviewing the charts. This study was approved by the Institutional Review Board, Hospital of Oriental Medicine, Kyung Hee University.

Of these individuals, 2080 underwent secondary classification of constitution by SCM specialists. While traditional Korean medical doctors classify Sasang Constitution based on clinical characteristics, QSCC $\mathrm{II}^{+}$, proven its reliability and validity, was developed and applied in order to overcome its flaws of subjectivity. At the same time, for the purpose of further precise classification of Sasang Constitution, only those who corresponded to both the result of QSCC II ${ }^{+}$and clinical diagnosis by SCM specialists were included. As a result, 627 of 2080 individuals were excluded from the sample due to discordance of the results, and remaining 1453 individuals with the same results from both 1st classification and 2nd classification were selected for the study.

However, 4 of the 1453 individuals that had identical classifications were excluded due to the omission of their anthropometric measurements or blood test results, and 6 individuals were excluded because they were under the Korean legal adult age of 20 years. Thus, a total of 1443 adults aged $\geq 20$ years were enrolled in this study.

The population of Taeyangin individuals is extremely low $(0.03-0.1 \%)(12,13)$; therefore, it is not possible to classify Taeyangin individuals using QSCC $\mathrm{II}^{+}$.
As a result, only data regarding the other three constitutions were evaluated in this study.

\section{Variables and Definitions}

The demographic and biological characteristics of the 1443 participates, including gender, age, height, weight, blood pressure, blood test results, past history and constitution, were investigated based on a review of medical records.

The subject's height and weight were measured at the health examination center while they were wearing thin clothes using an automatic anthropometric measuring device. The body mass index (BMI) was then calculated by dividing the weight of the patients in kilograms by the square of their height in meters. Blood pressure was measured at the right upper arm while in resting position using an automatic blood pressure measuring device. Hypertension was defined as a diastolic blood pressure $\geq 90 \mathrm{mmHg}$ or a systolic blood pressure $\geq 140 \mathrm{mmHg}$ or the acknowledgment of treatment for high blood pressure in accordance with the criteria of the 7th Report of the Joint National Committee on the Prevention, Detection, Evaluation and Treatment of High Blood Pressure (25). Fasting blood samples were taken from the vein in the morning after a fast of at least $8 \mathrm{~h}$. The plasma glucose, total cholesterol, triglycerides and HDL-cholesterol levels were then measured using a Hitachi 7600 Automatic Analyzer (Hitachi Co., Tokyo, Japan). Diabetes was defined as a fasting plasma glucose $\geq 126 \mathrm{mg} / \mathrm{dl}$ in accordance with the ADA criteria (2) or the acknowledgment of treatment for diabetes.

Classification of the Sasang Constitution was considered to be acceptable only if the primary result using QSCC $\mathrm{II}^{+}$and secondary result from SCM specialists agreed with each other. QSCC II is a self reporting survey method with 121 questions developed in 1996 to classify Sasang Constitution (22), and QSCC II ${ }^{+}$is a survey method that only makes use of 54 questions among all QSCC II questions that have been proved to have significance (23). The diagnostic discrimination abilities of the QSCC $\mathrm{II}^{+}$are $71.7 \%$ in Tae-eumin, $38.7 \%$ in Soyangin and $83.3 \%$ in Soeumin with an average of $64.4 \%$ (24).

\section{Statistical Analysis}

Individual variables were compared according to constitution using one-way ANOVA for continuous variables and a $\chi^{2}$ test for categorical variables. Scheffe's posthoc test was conducted when the continuous variables differed significantly $(P<0.05)$. A chi-squared test or Fisher's exact test was used to compare the prevalence of diabetes according to constitution. In addition, multiple logistic regression was used to calculate the ORs for diabetes after adjusting for gender, age, BMI, 
hypertension, total cholesterol, triglycerides and HDLcholesterol, which are known risk factors for diabetes. Age, BMI, total cholesterol, triglycerides and HDLcholesterol were included in all regression models as continuous variables. All statistical analyses were performed using SPSS (version 15.0 for Windows; SPSS Inc., Chicago, IL), and $P$ values $<0.05$ were considered to be statistically significant.

\section{Results}

\section{Characteristics of the Subjects}

Table 1 shows the characteristics of our study subjects according to constitution. Overall, the study subjects were composed of $24.1 \%$ Soeumin individuals, $29.0 \%$ Soyangin individuals and $46.9 \%$ Tae-eumin individuals. The mean values of known risk factors for diabetes were significantly higher in Tae-eumin individuals than in Soyangin or Soeumin individuals. Specifically, the mean BMI, systolic blood pressure, diastolic blood pressure, fasting plasma glucose, total cholesterol and triglycerides were found to be significantly higher in Tae-eumin individuals, followed by Soyangin and Soeumin individuals. Conversely, the HDL-cholesterol was significantly lower in Tae-eumin individuals, followed by Soyangin and Soeumin individuals.

\section{Prevalence of Diabetes}

Table 2 shows the prevalence of diabetes stratified by gender and constitution. The overall prevalence of diabetes in the study population was $7.2 \%$. In addition, the prevalence of diabetes was $8.7 \%$ in men and $5.7 \%$ in women $\left(\chi^{2}=4.73\right.$, df $\left.=1, P=0.030\right)$. Furthermore, the prevalence of diabetes also differed significantly according to constitution $\left(\chi^{2}=36.20, \quad \mathrm{df}=2, \quad P<0.001\right)$. Specifically, the prevalence of the disease was higher in
Tae-eumin (11.4\%) individuals than in Soyangin $(5.0 \%)$ or Soeumin $(1.7 \%)$ individuals. Finally, after dividing the subjects into men and women, the prevalence of diabetes differed significantly.

\section{Adjusted ORs for Diabetes}

The unadjusted and sequentially adjusted ORs for diabetes of various type individuals in comparison to Soeumin individuals are shown in Table 3. When compared with Soeumin individuals, Soyangin individuals had a higher OR for diabetes (OR 3.02, 95\% CI 1.20-7.56); however, this difference was not statistically significant after adjustment for other risk factors. In addition, when compared with Soeumin individuals, Tae-eumin individuals

Table 2. Prevalence of diabetes stratified by gender and constitution

\begin{tabular}{llllr}
\hline & \multicolumn{2}{l}{ Constitution } & & \\
\cline { 2 - 4 } Gender & \multicolumn{1}{l}{ Soeumin } & Soyangin & Tae-eumin & \multicolumn{1}{c}{$P$} \\
\hline Male & $4 \%(4 / 100)$ & $6.7 \%(18 / 270)$ & $11.7 \%(40 / 342)$ & 0.002 \\
Female & $0.8 \%(2 / 248)$ & $2.0 \%(3 / 148)$ & $11.0 \%(37 / 335)$ & $<0.001$ \\
Total & $1.7 \%(6 / 348)$ & $5.0 \%(21 / 418)$ & $11.4 \%(77 / 677)$ & $<0.001$ \\
\hline
\end{tabular}

Table 3. Adjusted ORs and $95 \%$ CIs for diabetes according to constitution

\begin{tabular}{llll}
\hline & Soeumin & Soyangin & Tae-eumin \\
\hline Model 1 & 1.0 & $3.02^{*}(1.20-7.56)$ & $7.32^{\dagger}(3.15-16.97)$ \\
Model 2 & 1.0 & $2.26(0.89-5.77)$ & $6.29^{\dagger}(2.69-14.71)$ \\
Model 3 & 1.0 & $1.98(0.77-5.12)$ & $4.13^{\dagger}(1.57-10.90)$ \\
Model 4 & 1.0 & $1.97(0.76-5.11)$ & $3.90^{\dagger}(1.47-10.33)$ \\
Model 5 & 1.0 & $2.01(0.77-5.26)$ & $3.96^{\dagger}(1.48-10.60)$ \\
\hline
\end{tabular}

Model 1 is unadjusted. Model 2 is adjusted for age and gender. Model 3 is adjusted for age, gender and BMI. Model 4 is adjusted for age, gender, BMI and hypertension. Model 5 is adjusted for age, gender, BMI, hypertension, total cholesterol, triglycerides and HDL-cholesterol. $* P<0.05 ;{ }^{\dagger} P<0.01$.

Table 1. Characteristics of the 1443 subjects according to constitution

\begin{tabular}{|c|c|c|c|c|}
\hline \multirow[b]{2}{*}{ Characteristics } & \multicolumn{3}{|l|}{ Constitution } & \multirow[b]{2}{*}{$P$} \\
\hline & Soeumin $(n=348)$ & Soyangin $(n=418)$ & Tae-eumin $(n=677)$ & \\
\hline Age (years) & $45.0 \pm 12.2^{\mathrm{a}, \mathrm{b}}$ & $47.2 \pm 11.5^{\mathrm{a}}$ & $47.3 \pm 11.7^{\mathrm{b}}$ & 0.005 \\
\hline Gender ( $\%$ male $)$ & 28.7 & 64.6 & 50.5 & $<0.001$ \\
\hline Height $(\mathrm{cm})$ & $160.0 \pm 8^{\mathrm{a}, \mathrm{b}}$ & $164.1 \pm 7.9^{\mathrm{a}}$ & $163.8 \pm 8.9^{\mathrm{b}}$ & $<0.001$ \\
\hline Weight $(\mathrm{kg})$ & $54.1 \pm 7.3^{\mathrm{a}, \mathrm{b}}$ & $61.9 \pm 7.9^{\mathrm{a}, \mathrm{c}}$ & $72.0 \pm 10.0^{\mathrm{b}, \mathrm{c}}$ & $<0.001$ \\
\hline Body mass index $\left(\mathrm{kg} / \mathrm{m}^{2}\right)$ & $21.1 \pm 2.2^{\mathrm{a}, \mathrm{b}}$ & $22.9 \pm 1.9^{\mathrm{a}, \mathrm{c}}$ & $26.8 \pm 2.6^{\mathrm{b}, \mathrm{c}}$ & $<0.001$ \\
\hline Systolic blood pressure $(\mathrm{mmHg})$ & $120.1 \pm 16.0^{\mathrm{a}, \mathrm{b}}$ & $125 \pm 16.5^{\mathrm{a}, \mathrm{c}}$ & $131.6 \pm 17.6^{\mathrm{b}, \mathrm{c}}$ & $<0.001$ \\
\hline Diastolic blood pressure (mmHg) & $74.9 \pm 10.7^{\mathrm{a}, \mathrm{b}}$ & $78.3 \pm 11.6^{\mathrm{a}, \mathrm{c}}$ & $81.5 \pm 11.5^{\mathrm{b}, \mathrm{c}}$ & $<0.001$ \\
\hline Fasting plasma glucose $(\mathrm{mg} / \mathrm{dl})$ & $89.6 \pm 11.2^{\mathrm{a}, \mathrm{b}}$ & $95.2 \pm 21.4^{\mathrm{a}, \mathrm{c}}$ & $101.3 \pm 30.5^{\mathrm{b}, \mathrm{c}}$ & $<0.001$ \\
\hline Total cholesterol $(\mathrm{mg} / \mathrm{dl})$ & $192 \pm 34.2^{\mathrm{a}, \mathrm{b}}$ & $198.9 \pm 35.5^{\mathrm{a}, \mathrm{c}}$ & $205.2 \pm 35.6^{\mathrm{b}, \mathrm{c}}$ & $<0.001$ \\
\hline Triglycerides $(\mathrm{mg} / \mathrm{dl})$ & $110.6 \pm 72.3^{\mathrm{a}, \mathrm{b}}$ & $137 \pm 90.2^{\mathrm{a}, \mathrm{c}}$ & $168.5 \pm 101.8^{\mathrm{b}, \mathrm{c}}$ & $<0.001$ \\
\hline HDL-cholesterol (mg/dl) & $49.6 \pm 10.9^{\mathrm{a}, \mathrm{b}}$ & $46.2 \pm 10.3^{\mathrm{a}, \mathrm{c}}$ & $43.2 \pm 9.5^{\mathrm{b}, \mathrm{c}}$ & $<0.001$ \\
\hline
\end{tabular}

Data shown are the means $\pm \mathrm{SD}$, unless otherwise indicated.

${ }^{\text {a }}$ Soeumin and Soyangin differ significantly.

${ }^{\text {b}}$ Soeumin and Tae-eumin differ significantly.

${ }^{\mathrm{c}}$ Soyangin and Tae-eumin differ significantly. 
had a higher OR for diabetes (OR 7.32, 95\% CI 3.15-16.97). However, the OR for diabetes for Taeeumin individuals decreased to $3.96 \quad(95 \%$ CI 1.48-10.60) after adjustment for gender, age, BMI, hypertension, total cholesterol, triglycerides and HDLcholesterol, but this value was still significantly higher than the OR of Soeumin individuals.

\section{Discussion}

In this cross-sectional study, we compared the prevalence and ORs of diabetes according to constitution and found that constitution may be an independent risk factor for diabetes. While the prevalence $(7.2 \%)$ of diabetes in all study subjects was similar to the age-adjusted prevalence $(7.6 \%)$ of diabetes in the Korean population (26), there was a significant difference in the prevalence of diabetes according to constitution. Specifically, more Tae-eumin individuals were afflicted with diabetes than Soyangin or Soeumin individuals.

There were two possible reasons for the difference in prevalence that was observed in this study. The first possible reason is that these findings may be indirect evidence of the theory of SCM, which states that there are differences in the susceptibility to pathological conditions according to constitution. Previous studies have shown that diabetes is associated with genetic disposition, such as family history of the disease or ethnicity (8-11). In addition, recent studies have shown that genetic polymorphism and constitutional information have significant relations each other (27-29). Therefore, the difference in the prevalence of diabetes according to constitution suggests that constitution could be an independent risk factor for diabetes similar to family history or ethnicity. However, it is also possible that the differences observed in this study may have been caused by other risk factors for diabetes than constitution. Obesity, hypertension and dyslipidemia are known risk factors for diabetes $(6,7)$, and the mean values of BMI, blood pressure and lipid levels were found to be significantly higher in Tae-eumin individuals than in Soyangin and Soeumin individuals in this study. Therefore, we used multiple logistic regression to determine the effect of constitution on diabetes after adjusting for known risk factors. After adjustment, Taeeumin individuals still had a significantly greater risk of diabetes than Soeumin individuals. These findings indicate that constitution may be an independent risk factor of diabetes.

It should be noted that this study had several limitations. One such limitation is that the diagnostic criteria of diabetes used in this study were not strict. Because the only diagnostic criteria suggested by the ADA that were used in the present study, was fasting plasma glucose, it is possible that the prevalence of diabetes observed in this study was smaller than the actual prevalence of diabetes.
Another possible limitation is that only individuals with constitutions that were identical when determined by QSCC $\mathrm{II}^{+}$analysis and evaluation by a SCM trained specialist were included in this study, which may have resulted in selection bias. The other possible limitation is that this study was unable to overcome the difficulty to precisely and fully illustrate general characteristics of Korean adult population because it was conducted at merely one specific general hospital targeting outpatients visiting for health examinations.

In conclusion, this study demonstrated that Sasang Constitution was significantly and independently associated with diabetes. These findings suggest that Sasang Constitution could be an independent risk factor for diabetes and that Sasang Constitution should be considered when detecting and treating the disease.

\section{References}

1. Wild S, Roglic G, Green A, Sicree R, King H. Global prevalence of diabetes: estimates for the year 2000 and projections for 2030 . Diabetes Care 2004;27:1047-53.

2. American Diabetes Association. Diagnosis and classification of Diabetes Mellitus. Diabetes Care 2008;31:S55-60.

3. World Health Organization. Definition and diagnosis of diabetes mellitus and intermediate hyperglycemia: report of a WHO/IDF consultation. Geneva, Switzerland: World Health Organization 2006.

4. Stratton IM, Adler AI, Neil HA, Matthews DR, Manley SE, Cull CA, et al. Association of glycaemia with macrovascular and microvascular complications of type 2 diabetes (UKPDS 35): prospective observational study. Br Med $J$ 2000;321:405-12.

5. American Diabetes Association. Economic Costs of Diabetes in the U.S. in 2007. Diabetes Care 2008;31:596-615.

6. American Diabetes Association. Screening for type 2 diabetes. Diabetes Care 2004;27:S11-4.

7. American Diabetes Association. Standards of Medical Care in Diabetes-2008. Diabetes Care 2008;31:S12-54.

8. Haffner SM. Epidemiology of type 2 diabetes: risk factors. Diabetes Care 1998;21:C3-6.

9. Harrison TA, Hindorff LA, Kim H, Wines RC, Bowen DJ, McGrath BB, et al. Family history of diabetes as a potential public health tool. Am J Prev Med 2003;24:152-9.

10. Meigs JB, Cupples LA, Wilson PW. Parental transmission of type 2 diabetes: the Framingham Offspring Study. Diabetes 2000;49: $2201-7$.

11. Valdez R, Yoon PW, Liu T, Khoury MJ. Family history and prevalence of diabetes in the U.S. population: the 6-year results from the National Health and Nutrition Examination Survey (1999-2004). Diabetes Care 2007;30:2517-22.

12. Lee JM. Dong-Yi-Soo-Se-Bo-Won. Seoul, Korea: Jae Ma Lee, 1894.

13. Lee JM. Choi S-H., trans. Longevity and Life Preservation in Oriental Medicine. Seoul, Korea: Kyung Hee University Press, 1996.

14. Chae H, Lyoo IK, Lee SJ, Cho S, Bae H, Hong M, et al. An alternative way to individualized medicine: psychological and physical traits of Sasang typology. J Altern Complement Med 2003;9:519-28.

15. Jung SI, Kim YW, Jung WG, Kim JW, Kim JI, Lim HJ. A clinical study about the diabetes mellitus patients according to the Sasang constitution. J Sasang Constitutional Med 2001;13:40-51.

16. Kim HW, Kim JH, Song JM. A clinical case report of diabetic patient with foot ulcers. J Sasang Constitutional Med 2002;14:132-7.

17. Jung SI, Lee HM, Kim JW. A clinical study about the diabetes mellitus patients' administration of Indongdeungjikolpitang. J Sasang Constitutional Med 2002;14:138-46.

18. Go WS, Kim KS, Lim EC. A case report on a patient diagnosed as diabetic foot. J Sasang Constitutional Med 2002;14:169-74. 
19. Hwang MW, Lee TG, Lim JH, Jung YJ, Kim SB, Lee SK, et al. A case study of Soyangin edematous patient diagnosed as diabetic nephropathy and treated Dojeokgangkitang. J Sasang Constitutional Med 2003;15:129-36.

20. Lee HM, Jo HS, Jeun SH, Kim JW. A clinical study of administration of mushroom yogurt on the Taeumin, diabetes mellitus patients. J Sasang Constitutional Med 2004;16:139-51.

21. Lee SG, Lee KL, Song JM. A case study of one patient who has diabetic gangrene in foot and finger due to diabetes. J Sasang Constitutional Med 2004;16:129-32.

22. Kim SH, Koh BH, Song IB. A study on the standardization of QSCC $\alpha$ (questionnaire for the Sasang Constitution Classification $\alpha$ ). J Korean Oriental Med Soc 1996;17:337-93.

23. Kim SB, Lee JH, Park GS, Jeong YJ, Lee SK, Song IB. A study on responses to the questionnaire based on of revised Sasang Constitutional Classification II (QSCC $\left.\mathrm{II}^{+}\right)$. J Sasang Constitutional Med 2001;13:15-22.

24. Jang DM. The Validation study of the QSCC II ${ }^{+}$Revised Questionnaire for the Sasang Constitution Classification II. Seoul, Korea: Kyung Hee University, 2003.
25. Chobanian AV, Bakris GL, Black HR, Cushman WC, Green LA, Izzo JL Jr, et al. The Seventh Report of the Joint National Committee on Prevention, Detection, Evaluation, and Treatment of High Blood Pressure: the JNC 7 report. JAMA 2003;289: 2560-72.

26. Kim SM, Lee JS, Lee J, Na JK, Han JH, Yoon DK, et al. Prevalence of diabetes and impaired fasting glucose in Korea: Korean National Health and Nutrition Survey 2001. Diabetes Care 2006;29:226-31.

27. Kwon TB, Whang CW, Sul IC, Lee KO, Hwang KY, Yang DH, et al. A study of HLA-DR polymorphism in four physical constitution groups classified by Korean traditional medicine. Korean J Med 2000;58:91-101.

28. Han SK, Chi SE, Choi SM. Study on the analysis of constitutional genes by HLA typing. J Sasang Constitutional Med 2001;13:97-103.

29. Han SK, Chi SE, Choi SM. A study on the analysis of constitutional genes. J Sasang Constitutional Med 2003;15:109-17.

Received March 12, 2009; accepted May 11, 2009 


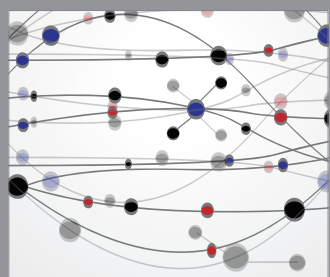

The Scientific World Journal
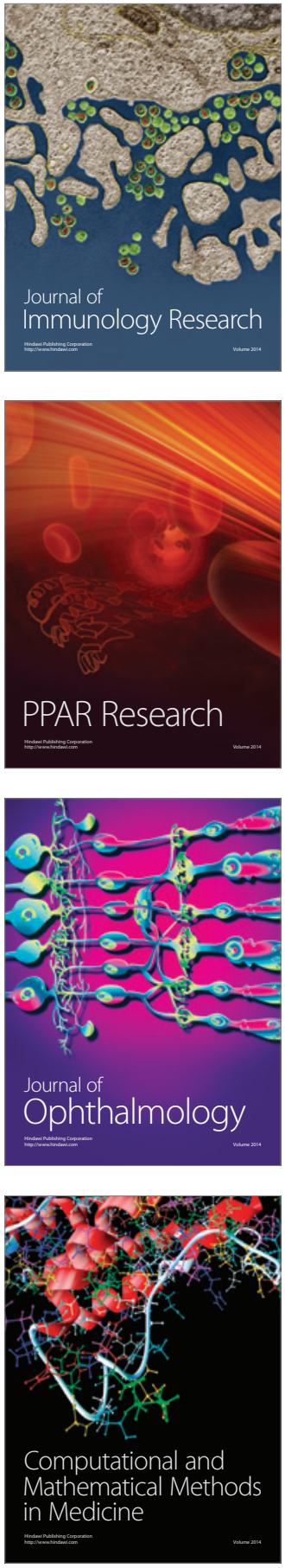

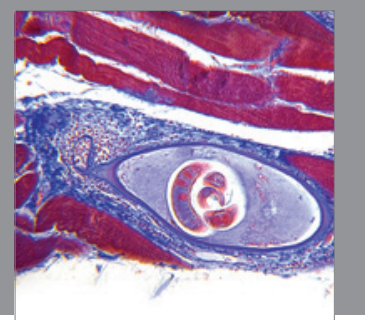

Gastroenterology

Research and Practice
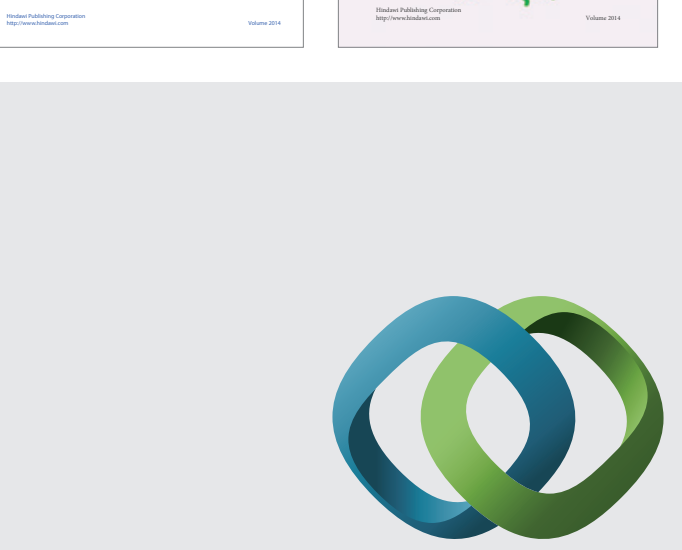

\section{Hindawi}

Submit your manuscripts at

http://www.hindawi.com
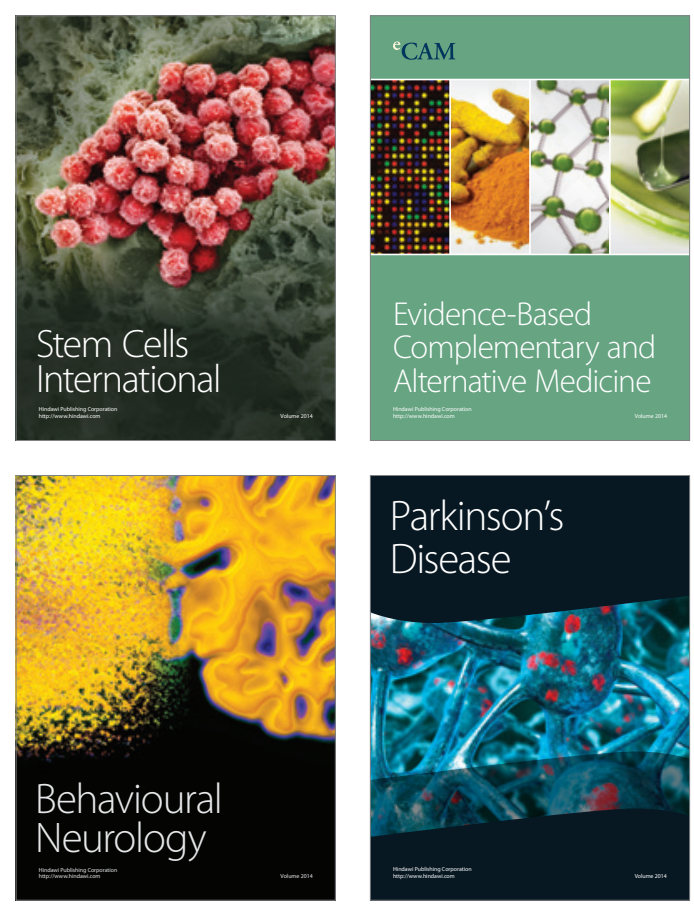

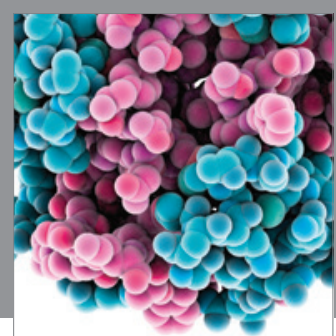

Journal of
Diabetes Research

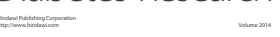

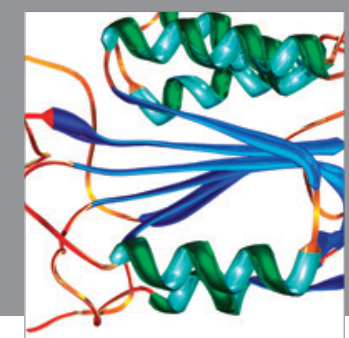

Disease Markers
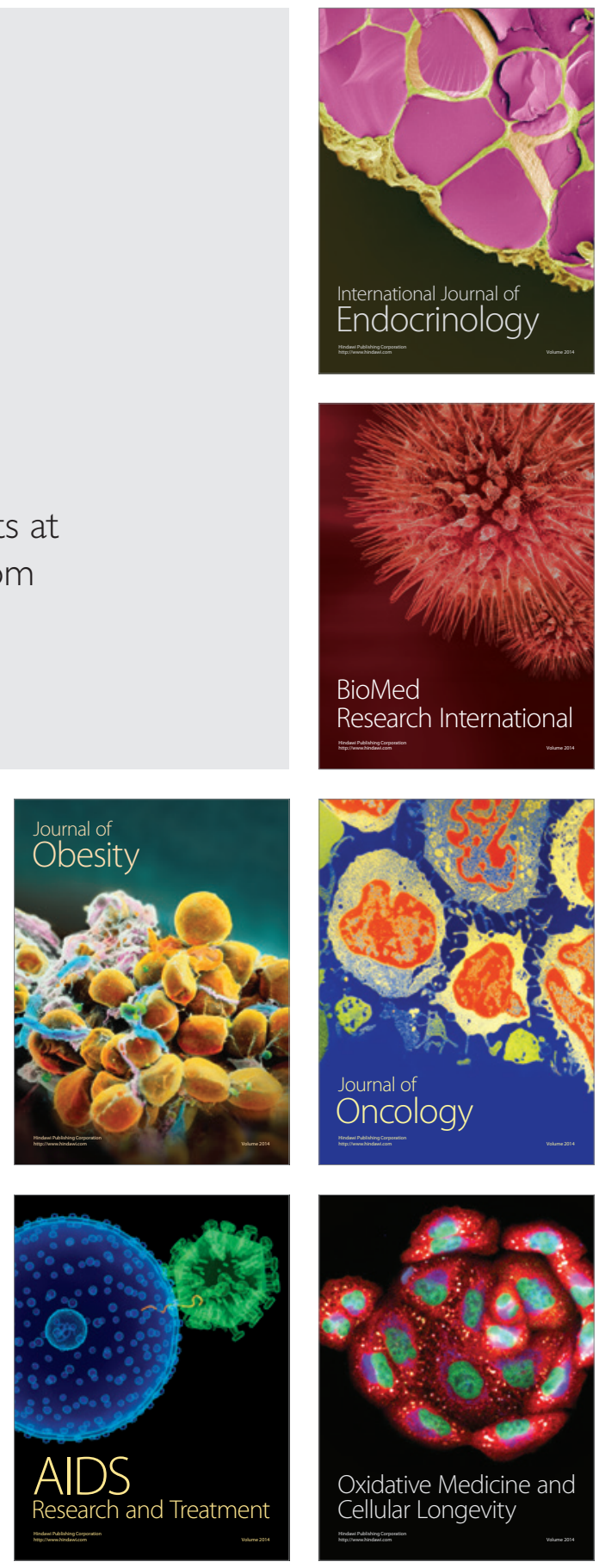